\title{
Multi-Physics Model Development for Polonium Transport Behavior in a Lead-Cooled Fast Reactor
}

\author{
Deng Lilin ${ }^{1}$, Wang Yuqing ${ }^{2}$, Zhai Zian ${ }^{1}$, Huang Bochen ${ }^{1}$, Wu Jiewei ${ }^{2,3}, \mathrm{He}$ Jianbo ${ }^{2}$ and \\ Ni Muyi ${ }^{2,3 *}$
}

${ }^{1}$ Science and Technology on Reactor System Design Technology Laboratory, Nuclear Power Institute of China, Chengdu, China, ${ }^{2}$ Sino-French Institute of Nuclear Engineering and Technology, Sun Yat-sen University, Guangzhou, China, ${ }^{3}$ The Institute of Advanced Science Facilities (IASF), Shenzhen, China

${ }^{210} \mathrm{Po}$, a highly toxic element with strong volatility, is one of the main source terms of a GenIV lead-cooled fast reactor (LFR). Therefore, the radioactive safety caused by ${ }^{210} \mathrm{Po}$ has become an important topic in LFR-related research. In order to simulate the behavior of ${ }^{210} \mathrm{Po}$ in an LFR, this work developed a multi-physics model of an LFR from the perspective of radioactive transport. Considering the effects of nuclide decay, cover gas leakage, containment ventilation, and Po aerosol deposition, a comprehensive simulation was carried out to evaluate the sensitivity of those effects on the ${ }^{210} \mathrm{Po}$ distribution in detail.

OPEN ACCESS

Edited by: Shanfang Huang,

Tsinghua University, China

Reviewed by: Feng Xie, Tsinghua University, China Qin Zeng, South China University of Technology, China

${ }^{*}$ Correspondence: Ni Muyi nimuyi@mail.sysu.edu.cn

Specialty section: This article was submitted to Nuclear Energy, a section of the journal Frontiers in Energy Research

Received: 19 May 2021 Accepted: 25 June 2021 Published: 30 July 2021

Citation: Lilin D, Yuqing W, Zian Z, Bochen H, Jiewei W, Jianbo H and Muyi N (2021) Multi-Physics Model Development for Polonium Transport Behavior in a Lead-Cooled Fast Reactor.

Front. Energy Res. 9:711916. doi: 10.3389/fenrg.2021.711916 Preliminary results indicate that during normal operation, most of the ${ }^{210} \mathrm{Po}$ in the LBE exist in the form of $\mathrm{PbPo}$, and around $10^{-9}$ of ${ }^{210} \mathrm{Po}$ could evaporate from the LBE into the cover gas, and then further leak into the containment. In addition, even if the leakage rate of ${ }^{210} \mathrm{Po}$ in the cover gas into the containment is maintained at $5 \%$ per day, due to the deposition of Po aerosol, the ${ }^{210} \mathrm{Po}$ contamination on the inner surface of the containment is still below the radioactivity concentration limits.

Keywords: polonium, LBE, fast reactor, Gen-IV, nuclear safety

\section{INTRODUCTION}

As one of the generation-IV (Gen-IV) nuclear power system, the lead-cooled fast reactor (LFR) is expected to be the first concept to achieve industrial demonstration (Lorusso et al., 2018; Nuclear Power, 2019). Lead-bismuth eutectic (LBE) is selected as the primary coolant for the LFR due to its neutronic economic and good thermal hydraulic properties (Dierckx et al., 2014). However, during normal operation of the LFR, ${ }^{210} \mathrm{Po}$, a highly toxic element with strong volatility, will be produced in the LBE coolant, which will induce a new radioactive safety problem.

In the purpose of the occupational safety and public health, ICRP and nuclear power countries have specified healthful working conditions and given the exposure limits of ${ }^{210} \mathrm{Po}$. In NRB-99 of Russia, the occupational annual limit on intake (ALI) is settled as $6.70 \times 10^{3} \mathrm{~Bq}$, and the safety permission of air concentration is below $2.7 \mathrm{~Bq} / \mathrm{m}^{3}$ (Pankratov et al., 2004). For the U.S. NRC regulation of $10 \mathrm{CFR}$ Part.20, the derived air concentration (DAC) of ${ }^{210}$ Po is settled as $1.1 \times 10^{5} \mathrm{~Bq} / \mathrm{m}^{3}$, while one DAC is equal to allowable maximum air concentration at the breathing rate of $1.3 \mathrm{~m}^{3} / \mathrm{h}$ for 2,000 working hours per year. And the ALI for ingestion and inhalation are $1.11 \times 10^{5} \mathrm{~Bq}$ and $2.22 \times 10^{4} \mathrm{~Bq}$, respectively (Nuclear Regulatory Commission 10CFR, 2017). In China, the National Standard GB18871-2002 rules mention the ALI of ${ }^{210} \mathrm{Po}$ as $8.3 \times 10^{4} \mathrm{~Bq}$, and the exemption concentration as $10^{4} \mathrm{~Bq}$ (Mao, 2014), the National regulation on ${ }^{210} \mathrm{Po}$ of RA, US, and CN are given in Table 1. 


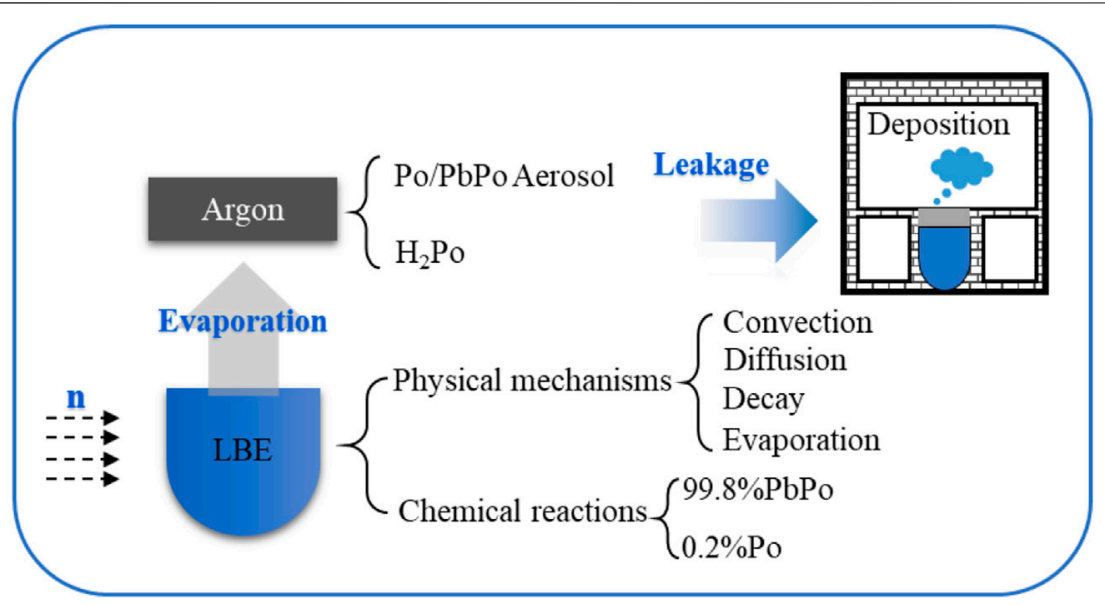

FIGURE 1 | Migration characteristics of polonium in the LBE reactor.

\section{MULTI-PHYSICS MODEL FOR PO TRANSPORT IN THE LFR}

\section{Source Term of Po in the LFR}

${ }^{210}$ Po has a short half-life of 138.4 days (Ram et al., 2019) and is the $\beta$ decay product of ${ }^{210} \mathrm{Bi}$ (Loewen, 2005). During the normal operation of the LFR, ${ }^{210}$ Po evaporates from the LBE coolant as a simple substance and a chemical form of $\mathrm{PbPo}$, and then accumulates in the cover gas. Accompanied with the leakage of cover gas, ${ }^{210} \mathrm{Po}$ is released into the containment (Feuerstein et al., 1992), which results in significant radioactive contamination and potential occupational exposure during maintenance.

$$
{ }^{209} \mathrm{Bi}+n \rightarrow{ }^{210} \mathrm{Bi} \underset{t_{1 / 2}=5 \text { days }}{\stackrel{\beta^{-}}{\longrightarrow}} \mathrm{Po} \underset{t_{1 / 2}=138.4 \text { days }}{\stackrel{\alpha}{\longrightarrow}} \mathrm{Pb} .
$$

\section{Po Behavior in the LFR}

\section{Physical and Chemical Properties of Po in the LFR} As shown in Figure 1, ${ }^{210}$ Po exists in the form of $\mathrm{Po}, \mathrm{PbPo}$, and $\mathrm{H}_{2} \mathrm{Po}$ in a typical LFR. And it is immediately apparent that the migration behavior is affected by the key processes of evaporation, decay, diffusion, convection in flow, deposition in air, and chemical reactions with other substances.

In LBE coolant, once the Po is generated from the ${ }^{210} \mathrm{Bi}$ decay, it will have a reaction with $\mathrm{Pb}$ immediately and form the compound of $\mathrm{PbPo}$ with stable chemical properties. For example, when the coolant temperature is around $673 \mathrm{~K}$, only $0.2 \%\left(\chi_{P o, L B E}\right)$ of Po in the LBE is left in the form of Po, and the remaining $99.8 \%\left(\chi_{P b P o, L B E}\right)$ is in the form of $\mathrm{PbPo}$. Both $\mathrm{Po}$ and $\mathrm{PbPo}$ can evaporate into the cover gas at a high temperature (Li et al., 1998; Buongiorno, 2001; Buongiorno et al., 2017), which is slow but non-neglectful from the perspective of radioactive safety.

For an accident condition, such as steam generator tube rupture (SGTR), PbPo may directly come in contact with steam, and highly volatile radioactive compounds such as $\mathrm{H}_{2} \mathrm{Po}$ will be produced, which will make the Po behavior even more complicated. The chemical equations are as follows:

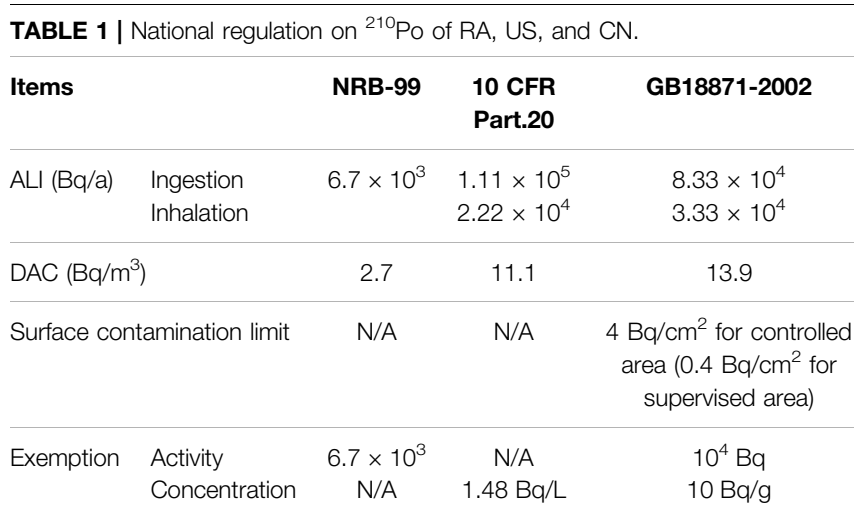

$$
\begin{gathered}
2 \mathrm{PbPo}_{(\text {sol })}+\text { heat } \leftrightarrow \mathrm{PbPo}(g)+\mathrm{Po}(g)+P b_{(s)}, \\
\mathrm{PbPo}+\mathrm{H}_{2} \mathrm{O} \leftrightarrow \mathrm{H}_{2} \mathrm{Po}(g)+\mathrm{PbO}_{(s o l)} .
\end{gathered}
$$

The fundamental properties of $\mathrm{Po}, \mathrm{PbPo}$, and $\mathrm{H}_{2} \mathrm{Po}$ are summarized in Table 2.

\section{Mass Flow of Po in LFR}

To gain insight into the characteristic feature of ${ }^{210} \mathrm{Po}$ in LFR on a normal operation, the mass flow map of ${ }^{210} \mathrm{Po}$ had been clearly drawn in Figure 2.

In LBE coolant,

- Accompanied with neutron irradiation, the isotope ${ }^{210} \mathrm{Bi}$ is produced, and then we have the concentration of $\mathrm{Bi}$ as $c_{B i 210}$ $\left(\mathrm{mol} / \mathrm{m}^{3}\right)$, with a decay rate $\lambda_{B i 210}$ of $1.6 \times 10^{-6}(1 / \mathrm{s})$;

- ${ }^{210} \mathrm{Bi}$ decays into ${ }^{210} \mathrm{Po}$, then we have the concentration of Po as $c_{i}^{L B E}\left(\mathrm{~mol} / \mathrm{m}^{3}\right)$, where the species $i$ means Po or PbPo;

- Define the decay of Po, $J_{\text {decay }}^{L B E}=\lambda_{P o} \cdot c_{i}^{L B E}\left(\mathrm{~mol} / \mathrm{m}^{3} \mathrm{~s}\right)$;

- Define the purification rate of Po in LBE, $J_{\text {puri }}^{L B E}=\eta_{L B E} \cdot c_{i}^{L B E}$ $\left(\mathrm{mol} / \mathrm{m}^{3} \mathrm{~s}\right)$ 


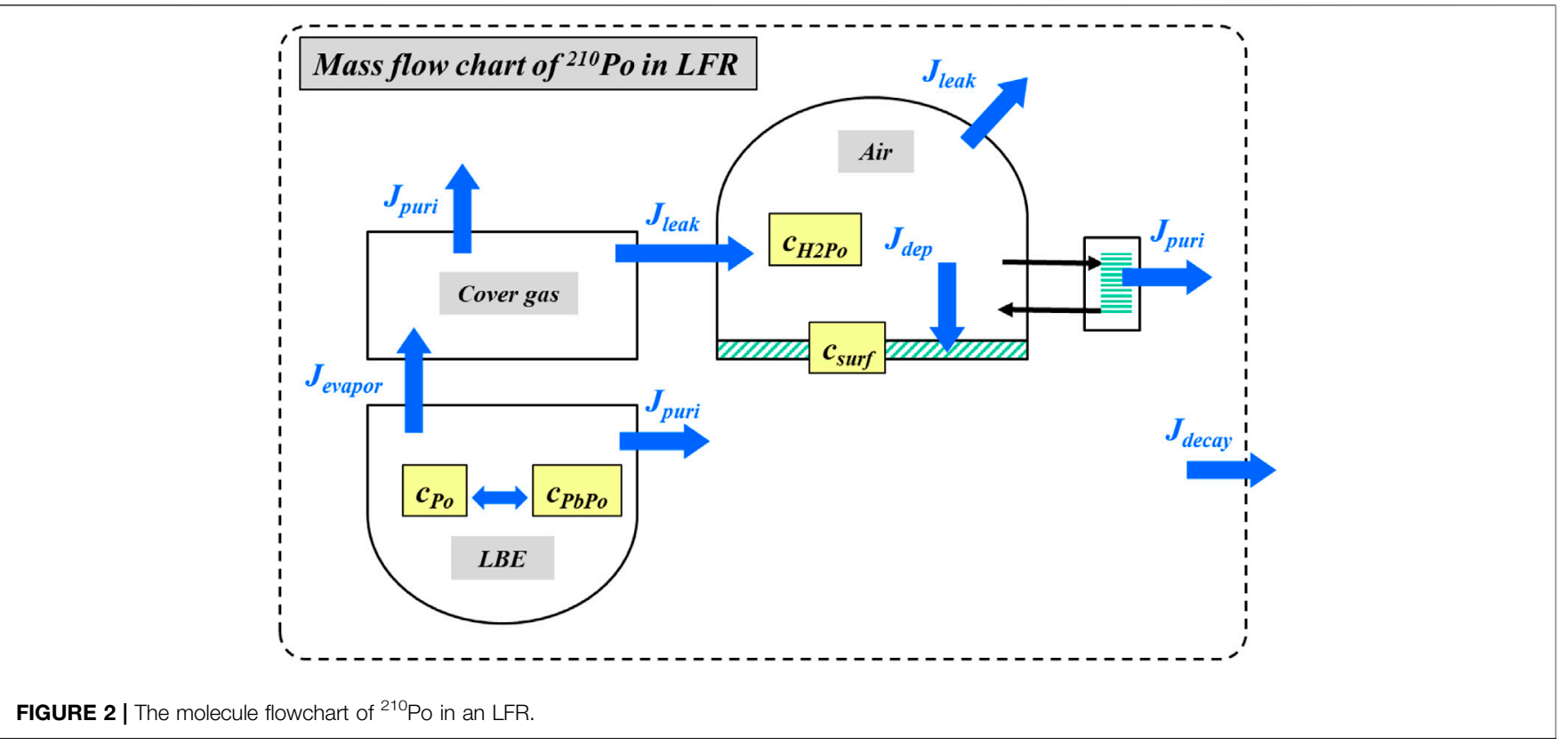

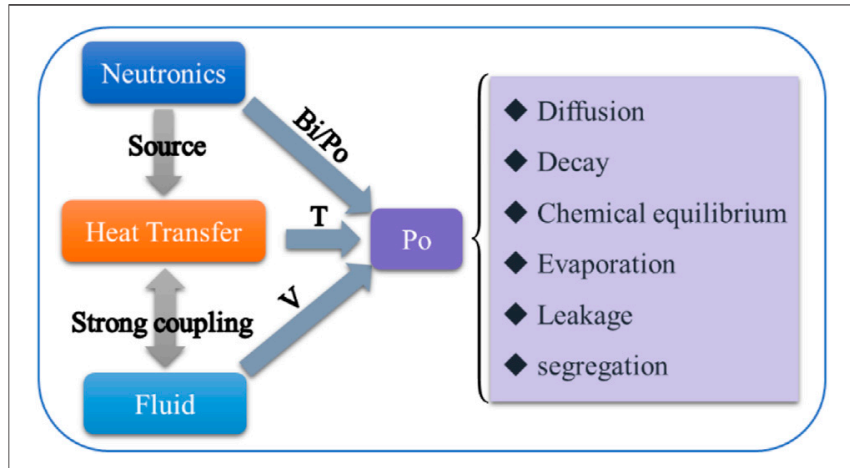

FIGURE 3 | The multi-physics model of Po migration in an LFR.

- Define the Po and PbPo evaporate flux into cover gas at the LBE-gas interface as $\left.J_{i, v a p o r}\right|_{\text {interface }}\left(\mathrm{mol} / \mathrm{m}^{2} \mathrm{~s}\right)$;

Then the molecule balance equation for each species in LBE can be written as Eq. 4:

$$
\frac{d c_{i}^{L B E}}{d t}=\chi_{i} \lambda_{B i 210} c_{B i 210}-\left(J_{\text {puri }}^{L B E}+J_{\text {decay }}^{L B E}+J_{\text {leak }}^{L B E}+\left.J_{i, \text { vapor }}\right|_{\text {interface }}\right)
$$

In cover gas.

- Define the decay rate of Po, $J_{\text {decay }}^{\text {gas }}=\lambda_{P o} \cdot c_{i}^{\text {gas }}\left(\mathrm{mol} / \mathrm{m}^{3} \mathrm{~s}\right)$;

- Define the purification rate of Po, $J_{\text {puri }}^{\text {gas }}=\eta_{\text {gas }} \cdot c_{i}^{\text {gas }}\left(\mathrm{mol} / \mathrm{m}^{3} \mathrm{~s}\right)$;

- Define the leakage rate of Po into the containment, $J_{\text {leak }}^{\text {gas }}$ $\left(\mathrm{mol} / \mathrm{m}^{3} \mathrm{~s}\right)$

Then the molecule balance equation for each species in cover gas can be written as Eq. 5:

$$
\frac{d c_{i}^{\text {gas }}}{d t}=\left.J_{i, \text { vapor }}\right|_{\text {interface }}-\left(J_{\text {puri }}^{\text {gas }}+J_{\text {decay }}^{\text {gas }}+J_{\text {leak }}^{\text {gas }}\right)
$$

In containment.

- All the PbPo are assumed to be reacted with $\mathrm{H}_{2} \mathrm{O}$ in air, to generate $\mathrm{H}_{2} \mathrm{Po}$ in the containment, $c_{\mathrm{H}_{2} \mathrm{Po}}\left(\mathrm{mol} / \mathrm{m}^{3}\right)$;

- Define the decay rate of $\mathrm{H}_{2} \mathrm{Po}, J_{\text {decay }}^{\text {air }}\left(\mathrm{mol} / \mathrm{m}^{3} \mathrm{~s}\right)$;

- Define the deposition rate of $\mathrm{H}_{2} \mathrm{Po}, J_{d e p}^{a i r}=\lambda_{d e p} \cdot c_{\mathrm{H}_{2} \mathrm{Po}}^{a i r}$ $\left(\mathrm{mol} / \mathrm{m}^{3} \mathrm{~s}\right)$

- Define the purification rate $J_{\text {puri }}^{a i r}$ and leakage rate $J_{\text {leak }}^{\text {gas }}$ of $\mathrm{H}_{2} \mathrm{Po}$ in the containment.

Then the molecule balance equation for each species in the containment can be written as Eq. 6:

$$
\frac{d c_{H_{2} P o}^{a i r}}{d t}=J_{\text {leak }}^{\text {gas }}-\left(J_{\text {puri }}^{a i r}+J_{\text {dep }}^{a i r}+J_{\text {decay }}^{a i r}+J_{\text {leak }}^{a i r}\right)
$$

And due to the $\mathrm{H}_{2} \mathrm{Po}$ aerosol deposition, there will be surface contamination on the ground of the containment, which is calculated as follows:

$$
\frac{d c_{\mathrm{H}_{2} P o}^{\text {ground }}}{d t}=J_{d e p}^{a i r}-J_{\text {decay }}^{a i r}
$$

From above Eqs. 4-7, a numerical relationship between the ${ }^{210}$ Po transport and multi-physics environment of LFR had been finally established.

Then a particular emphasis should be put on the evaporation model of $\mathrm{Po}$ and $\mathrm{PbPo}$, which dominates how much of the ${ }^{210} \mathrm{Po}$ source will escape from the restraint of LBE. According to Raoult's law for ideal gas, the vapor pressure of dilute solution is equal to the vapor pressure of a pure solvent multiplied by the mole fraction of the solvent in solution at the special temperature (Feuerstein et al., 1992; Loewen, 2005). And the saturated vapor pressure, which is frequently cited, is listed in Table 2. 
TABLE 2 | Po, PbPo, and $\mathrm{H}_{2} \mathrm{Po}$ foundation properties (Feuerstein et al., 1992).

\begin{tabular}{|c|c|c|c|}
\hline & Po & $\mathrm{PbPo}$ & $\mathrm{H}_{2} \mathrm{Po}$ \\
\hline Density $\left[\mathrm{g} / \mathrm{cm}^{3}\right]$ & $9.2-9.4_{(\mathrm{sol})}$ & $9.6_{(\text {sol) }}$ & Gaseous \\
\hline Melting point $\left[{ }^{\circ} \mathrm{C}\right]$ & 250 & 600 & -36 \\
\hline Boiling point $\left[{ }^{\circ} \mathrm{C}\right]$ & 962 & 1,520 & 37 \\
\hline Saturated vapor pressure (Li et al., 1998) $\log P[\mathrm{~Pa}]$ & $-\frac{5440}{T[K]}+9.46^{\mathrm{a}}$ & $-\frac{6790}{T[K]}+8.46^{b}$ & - \\
\hline
\end{tabular}

${ }^{a} \mathrm{Po}$ vapor pressure experimentally measured in the temperature range of $368-604^{\circ} \mathrm{C}$.

${ }^{b} \mathrm{PbPo}$ vapor pressure experimental measured in the temperature range of $400-550^{\circ} \mathrm{C}$.

$$
P_{i, s a t}=x_{i, L B E} P_{i}
$$

There is a general consensus that the evaporation equilibrium of $\mathrm{Pb} / \mathrm{PbPo}$ can always be achieved in microscale on the surface of LBE coolant. Then the evaporation flux can be constructed as an equation of saturated vapor pressure andreal-time vapor pressure.

$$
\left.J_{i, \text { vapor }}\right|_{\text {interface }}=J_{i, 0} \times c_{i, L B E} \times \frac{P_{i, \text { sat }}-P_{i, g a s}}{P_{i, \text { sat }}},
$$

where $P_{i, g a s}$ is the partial pressure of $\mathrm{i}$ in cover gas, $P_{i}$ is the saturated vapor pressure of pure $i, x_{i}$ is the mole ratio of solute $i$ in solvent LBE, $P_{i, s a t}$ is the saturated vapor pressure of solute $i$ in solvent $\mathrm{LBE}$, and $J_{i, 0}$ is the evaporation rate of Po in vacuum, and because of the cover gas in the LFR, the evaporation rate of Po and $\mathrm{PbPo}$ is four orders of magnitude lower than that in vacuum.

\section{Multi-Physics Frame and Numerical Models Multi-Physics Frame}

In order to provide the specific parameters in the multi-physical field, the multi-physics coupling frame was established and the causal link between each physics had been found out in Figure 3 . The flow field and the heat transfer field are coupled strongly, while the flow heat transfer field and the concentration field are coupled weakly. By taking the output of thermal fluid ( $\vec{u}$ and T) as the input of the ${ }^{210} \mathrm{Po}$ molecule transfer, the ${ }^{210} \mathrm{Po}$ concentration and flux in both the steady state and the dynamic state can finally be obtained.

A two-dimensional axisymmetric geometric structure is utilized in this model, according to the typical LFR concept. The main components that have an effect on the source term transport behavior are taken into consideration, including reactor core, heat exchanger, pump, purification system, cover gas, and containment. The material library covers the main candidate materials used in the LFR.

\section{Fluid Flow Model}

In order to improve the utilization of computing resources, a porous medium model is modified to the descript ${ }^{210} \mathrm{Po}$ behavior in core and heat exchanger (HX), and the algebraic $\mathrm{y}+$ model is utilized to compute the LBE turbulence, which can couple porous media and laminar flow automatically. In reality, a porous media model is frequently adopted in the nuclear industry to simulate the reactor core or $\mathrm{HX}$, which validates a good agreement with the operation condition (Koloszar et al., 2014). The governing equations of the LBE flow are shown as follows:

$$
\begin{gathered}
\rho \frac{\partial \mathrm{u}}{\partial t}+\rho(\mathrm{u} \cdot \nabla) \mathrm{u}=\nabla \cdot[-P \mathrm{l}+\mathrm{k}]+\mathrm{F}+\rho \mathrm{g}, \\
\frac{\partial \rho}{\partial t}+\nabla \cdot(\rho \mathrm{u})=0
\end{gathered}
$$

The first equation is the momentum conservation equation, and the second equation is the mass conservation equation. The Brinkman equation is used to describe the fast flow in saturated porous media, where $\rho$ is the density $\left(\mathrm{kg} / \mathrm{m}^{3}\right)$, $\mathrm{u}$ is the velocity vector $(\mathrm{m} / \mathrm{s}), \quad \mathbf{P}$ is the pressure $(\mathrm{Pa}), \kappa$ is the Brinkman's permeability $\left(\mathrm{m}^{2}\right), \mathrm{F}$ is the volume force vector $\left(\mathrm{N} / \mathrm{m}^{3}\right)$, and $\mathrm{g}$ is the acceleration of gravity $\left(\mathrm{m} / \mathrm{s}^{2}\right)$.

The real reactor core is assembled by of tens of thousands of fuel rods vertically. In the simulation, we reasonably simplified the structure of the reactor core and HX as anisotropic porous media, and assumed that LBE flows out mainly from the $\mathrm{z}$-axial direction but rarely from the $\mathrm{r}$-axial direction. Then properties of porous media are determined by two physical quantities, that is, porosity and permeability. The real porosity of the LBE reactor core is $0.2-0.4$ (Koloszar et al., 2015). In this model, the porosity of the core is 0.3 and the porosity of the HX is 0.62 (Koloszar et al., 2014). And the permeability is calculated by Darcy's formula, which is given as follows:

$$
\kappa_{i}=\frac{Q}{\rho} \mu L_{i} / \Delta P_{i} A_{i},
$$

where $\mathrm{Q}$ is the mass flow $(\mathrm{kg} / \mathrm{s}), \mu$ is the dynamic viscosity $(\mathrm{Pa} \cdot \mathrm{s})$, $L_{i}$ is the flow length of the core or $\mathrm{HX}(\mathrm{m}), \Delta P_{i}$ is the pressure drop of the core or $\mathrm{HX}(\mathrm{Pa})$, and $A_{i}$ is the cross-sectional area of the core or $\mathrm{HX}\left(\mathrm{m}^{2}\right)$. The $\mathrm{z}$-axial leakage rate of the core is calculated as $9.4 \times 10^{-9} \mathrm{~m}^{2} \sim 1.04 \times 10^{-8} \mathrm{~m}^{2}$ and the $\mathrm{z}$-axial permeability of the HX is $3.65 \times 10^{-8} \mathrm{~m}^{2} \sim 4 \times 10^{-8} \mathrm{~m}^{2}$; since it is assumed that rare permeation occurs in the $\mathrm{r}$-axial direction, the r-permeability is set as $1 \times 10^{-12} \mathrm{~m}^{2}$.

Finally, the LBE coolant circulation in a reactor vessel was established. Heated by the reactor core and driven by buoyance, the LBE coolant flows up. Then driven by the pump, the LBE coolant will flow down, through HX, and back to the core. The entire flow field $(\vec{u})$ of LFR was obtained.

\section{Heat Transfer Model}

The heat transfer model is also based on a porous medium model, and the general governing equation of heat transfer is as follows:

$$
\begin{gathered}
\left(\rho C_{p}\right) \frac{\partial T}{\partial t}+\rho C_{p} \mathrm{u} \cdot \nabla \cdot \mathrm{q}=Q_{\text {heat }}, \\
\mathrm{q}=-k_{\text {eff }} \nabla T,
\end{gathered}
$$


TABLE 3 | Operation parameters of CLEAR, SVBR, MYRRHA, and CASE in this work (Zrodnikov et al., 2008; Zrodnikov et al., 2011; Didier et al., 2015).

\begin{tabular}{|c|c|c|c|c|}
\hline Design parameters & CLEAR-I & SVBR-100 & MYRRHA & CASE \\
\hline Country & CHINA & RUSSIA & BELGIUM & $\mathrm{CHINA}$ \\
\hline Thermal capacity (MWth) & 10 & 280 & 100 & 100 \\
\hline System pressure (MPa) & 0.05 & 6.7 & 0.17 (core) & 3 \\
\hline Coolant temp. at core inlet/outlet $\left({ }^{\circ} \mathrm{C}\right)$ & $260 / 390$ & $340 / 490$ & $270 / 410$ & $250 / 350$ \\
\hline Primary circulation & Natural & Forced & Natural & Forced \\
\hline Reactor vessel: $\mathrm{D} \times \mathrm{H}(\mathrm{m})$ & - & $4.53 / 6.92$ & $8.0 / 12$ & $5 / 7$ \\
\hline Flow rate of LBE coolant $(\mathrm{kg} / \mathrm{s})$ & 529.5 & 11,760 & 9,400 & 529.5 \\
\hline Core: $\mathrm{D} \times \mathrm{H}(\mathrm{m})$ & - & $1.645 / 0.9$ & $1.83 / 1.75$ & $1.4 / 1.75$ \\
\hline LBE inventory (ton) & 700 & 18.4 & 4,500 & 110 \\
\hline Average coolant flow rate $(\mathrm{m} / \mathrm{s})$ & - & - & 0.55 & 0.27 \\
\hline The highest coolant flow rate $(\mathrm{m} / \mathrm{s})$ & - & - & 2.37 & 1.88 \\
\hline
\end{tabular}

where $C_{p}$ is the specific heat capacity at a constant pressure $(\mathrm{J} / \mathrm{kg} \cdot \mathrm{K}), \mathrm{q}$ is the heat flux by conduction $\left(\mathrm{W} / \mathrm{m}^{2}\right), Q_{\text {heat }}$ is the heat sources as the reactor core and $\mathrm{HX}\left(\mathrm{W} / \mathrm{m}^{3}\right)$, and $k_{\text {eff }}$ is the effective thermal conductivity $(\mathrm{W} / \mathrm{m} \cdot \mathrm{K})$. The HX takes all the thermal power generated by the core to the secondary loop. The heat source of the HX can be calculated theoretically as follows:

$$
Q_{H X}=\frac{-K_{H X}\left(\frac{T_{\text {in }}+T_{\text {out }}}{2}-T_{2}\right)}{L_{H X}},
$$

where $Q_{H X}$ is the total heat transfer power of the $\mathrm{HX}\left(\mathrm{W} / \mathrm{m}^{3}\right)$, $K_{H X}$ is the total heat transfer coefficient $\left(\mathrm{W} / \mathrm{m}^{2} \cdot \mathrm{K}\right), T_{\text {in }}$ is the temperature that flows into the $\mathrm{HX}(\mathrm{K}), T_{\text {out }}$ is the temperature out of the $\mathrm{HX}(\mathrm{K}), T_{2}$ is the temperature of the secondary loop $(\mathrm{K})$, and $L_{H X}$ is the flow length of HX (m).

\section{Molecule Transfer Model}

Since $\vec{u}$ and $\mathrm{T}$ of the whole LFR are obtained from the computation of Eqs. 10, 13, the governing equation for the ${ }^{210}$ Po transport model can be written as follows:

$$
\frac{\partial c_{i}}{\partial t}+\nabla \cdot\left(J_{i, d i f f}+\mathrm{u} c_{i}\right)=R_{i}-\left.J_{i, v a p o r}\right|_{\text {interface }}
$$

where $c_{i}$ is the concentration of $\mathrm{i}\left(\mathrm{mol} / \mathrm{m}^{3}\right), \mathrm{J}_{i, \text { diff }}$ is the diffusive flux vector $\left(\mathrm{mol} / \mathrm{m}^{2} \cdot \mathrm{s}\right)$, and $R_{i}$ is a production or consumption rate expression $\left(\mathrm{mol} / \mathrm{m}^{3} \cdot \mathrm{s}\right)$.

\section{Numerical Modeling for ${ }^{210} \mathrm{Po}$ in a Typical LFR Modeling Condition}

In order to provide input for a simulation case, several typical LFR concepts in the world are investigated, and the main operation parameters are listed in Table 3 (Zrodnikov et al., 2008; Zrodnikov et al., 2011; Didier et al., 2015). The typical ventilation rate is one volume turnover per hour according to the PWR operation experience. In this work, we assume an atmosphere purification system for the containment, which has a ventilation rate of $0.5 / \mathrm{h}$ and ${ }^{210}$ Po remove efficiency of $95 \%$. According to IPPE experience, lifetimes of ${ }^{210} \mathrm{Po}$ aerosol range from $60-80 \mathrm{~s}$ on equipment to $100-150 \mathrm{~s}$ in the containment room. And practically, the aerosol lifetimes are usually selected as $100 \mathrm{~s}$ for calculation (Yefimov et al.,
1997). Besides, the influence of leakage is also the key factor that has to be taken into consideration. As a baseline, the leakage rate of cover gas is assumed as 5\%o per day, and the leakage rate of the containment is assumed as $4 \%$ per day.

\section{${ }^{210} \mathrm{Po}$ Distribution in LFR}

Under a normal operation condition, the temperature field of LBE ranges from 610 to $670 \mathrm{~K}$, and on the surface for $\mathrm{Po} / \mathrm{PbPo}$ evaporation, it is around $660 \mathrm{~K}$. The high-temperature LBE flows up out of the core and down into the HX and is then driven by the main pump flows back into the core. This is the primary cooling loop of the LBE in the reactor vessel. Then we coupled the LBE thermal fluid with cover gas to figure out the entire temperature field and velocity field in the LFR vessel, as shown in Figures 4, 5.

Then the ${ }^{210} \mathrm{Po}$ concentration field and transport map were computed with environmental inputs of $\vec{u}$ and T. And the results at a steady state are shown in Figure 6. ${ }^{210} \mathrm{Po}$ is evenly distributed in the reactor vessel and containment, except for a small amount of high concentration areas.

As shown in Figure 7, the average concentration of ${ }^{210} \mathrm{Po}$ in LBE vs. time is calculated during 100 days from start-up. Under normal conditions, the ${ }^{210} \mathrm{Po}$ concentration will reach equilibrium within 30 days. And the concentration of $\mathrm{Po}$ in LBE is around $1.08 \times 10^{10} \mathrm{~Bq} / \mathrm{kg}$, which is far beyond the exemption concentration according to Chinese regulation (GB18871-2002). In cover gas, the Po concentration is $6.58 \times$ $10^{3} \mathrm{~Bq} / \mathrm{L}$, which is also $2-3$ orders of magnitude higher than one $\mathrm{DAC}$ value. The concentration of Po in the containment is $\sim 1 \times$ $10^{-3} \mathrm{~Bq} / \mathrm{L}$, which is below the limitation in law.

\section{Impact Factors of the Po Transport Operation Temperature}

Since the $\mathrm{Po} / \mathrm{PbPo}$ evaporation rate is very sensitive to temperature, the influence of operation temperature is taken into analysis. Six different temperature ranges for LFR operation were simulated by adjusting the efficiency of the HX. And the corresponding average concentrations of ${ }^{210} \mathrm{Po}$ in cover gas and containment were obtained, which is shown in Figure 8.

Apparently, from Figure 8, a simple conclusion can be made that the evaporation rate of ${ }^{210}$ Po from LBE to cover gas will increase rapidly with the higher temperature on the LBE-gas interface. While the ${ }^{210} \mathrm{Po}$ concentration in cover gas is increasing, the ${ }^{210} \mathrm{Po}$ 

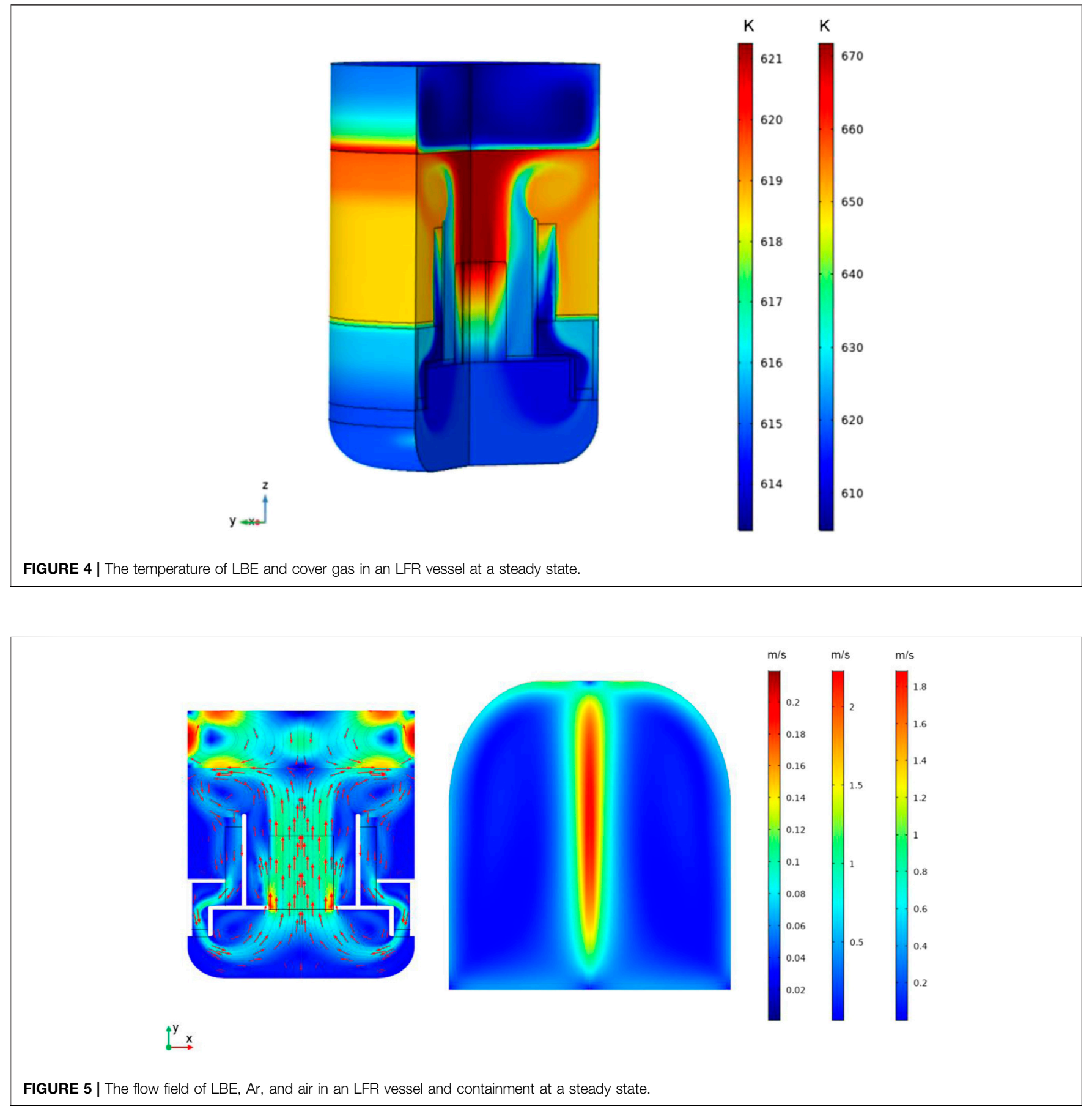

concentration in the containment is increasing in the same proportion. However, at high operation temperature like $401-467^{\circ} \mathrm{C}$, the concentration of ${ }^{210} \mathrm{Po}$ in the containment is 63.2 $\mathrm{Bq} / \mathrm{L}$, which is a bit higher than one $\mathrm{DAC}$ value.

\section{Deposition Rate}

A comprehensive analysis was made for all the influential factors (including deposition, ventilation, leakage, and decay) on the ${ }^{210} \mathrm{Po}$ concentration in the containment, which is shown in Table 4. It is obvious that the phenomenon of aerosol deposition is the key process affecting aerosol concentration in containment, based on the assumption in this work. However, the aerosol deposition rate is strongly dependent on the dynamic particle size and density, which will guide our future experiment.

We simulated the total surface contamination due to ${ }^{210} \mathrm{Po}$ deposition in the containment and its accumulation during 100 days normal operation. As shown in Figure 9, after 10 days operation, the ${ }^{210}$ Po activity on the ground of the containment exceeds the limit value of $4 \times 10^{3} \mathrm{~Bq} / \mathrm{m}^{2}$ specified in the China regulation GB18871-2002. Therefore, it is very important that 


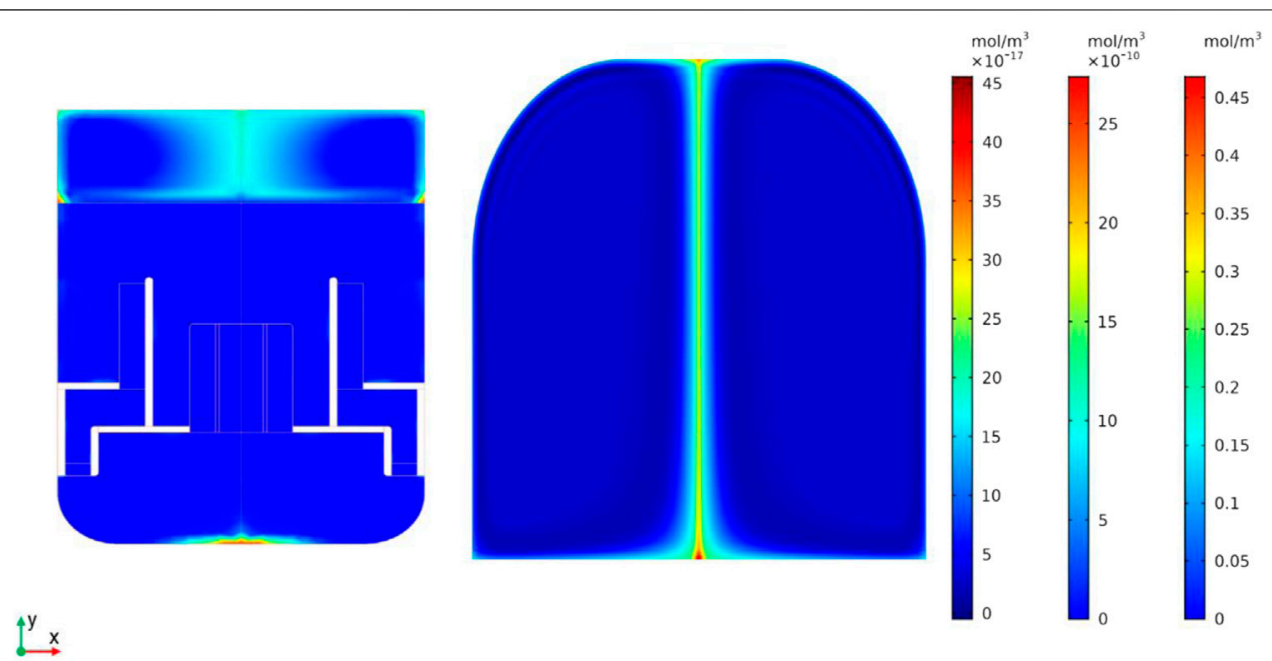

FIGURE 6 | The ${ }^{210} \mathrm{Po}$ transport in LFR vessel and containment at a steady state.

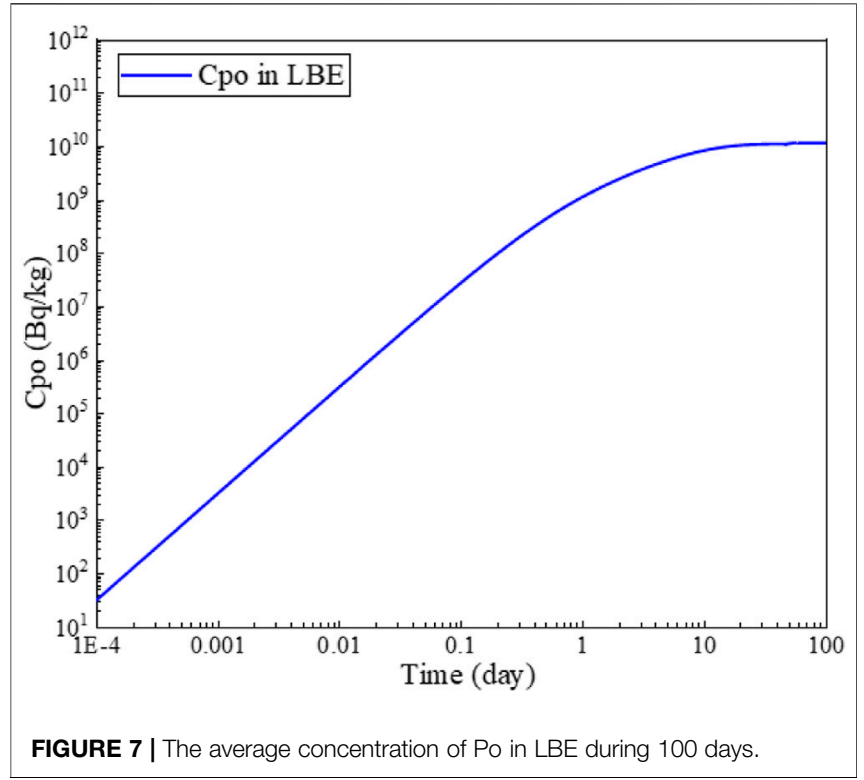

special decontamination measures must be developed to control the ${ }^{210} \mathrm{Po}$ and avoid radioactivity harms to maintenance staff.

\section{Leakage Rate}

In the real operation, the problem of cover gas leakage is inevitable. In order to better study the influence of leakage from the safety perspective, the leakage fraction per day of cover gas was varied from $0.01 \%$ to $0.02,0.04,0.08,0.16$, and $0.32 \%$; the ${ }^{210}$ Po activity in the containment was calculated; and the parameter sensitivity was taken in the analysis.

In Figure 10, the average activity of ${ }^{210} \mathrm{Po}$ in the containment is very sensitive to the leakage rate of the cover gas. Once the leakage rate is higher than 0.01 , the ${ }^{210} \mathrm{Po}$ activity in air will exceed the one DAC limit. In order

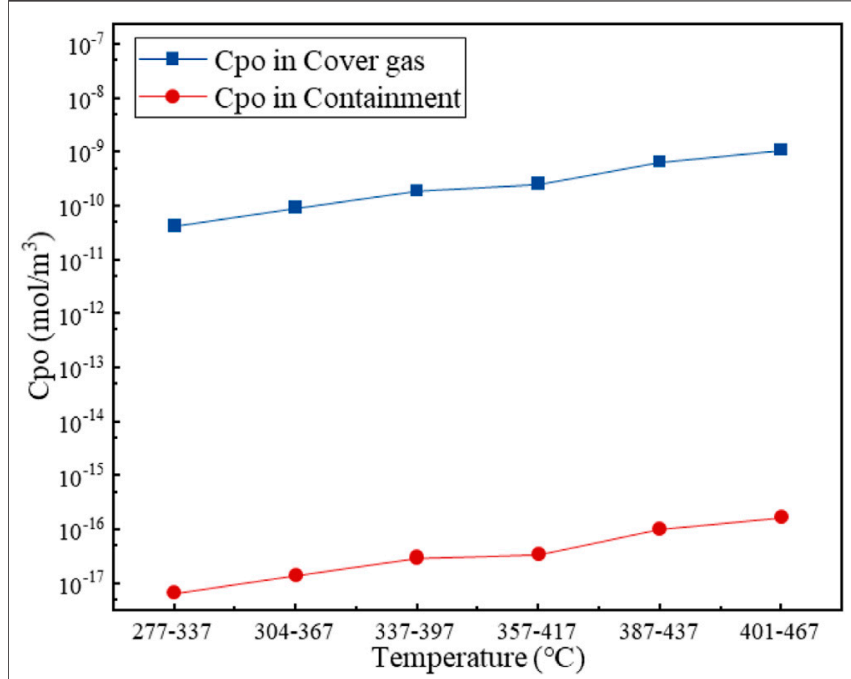

FIGURE 8 | The average concentration of Po in cover gas and containment under different temperature of evaporating interface.

TABLE 4 | Influence factors on ${ }^{210} \mathrm{Po}$ concentration in the containment.

Factors

Decay

Ventilation

Deposition

Leakage

to control the ${ }^{210}$ Po release and ensure the LFR in a safety state, the leakage rate of the cover gas should be kept below 0.01 strictly, and as low as possible. In case of serious radioactive leakage, the purification system should be quickly started to control the ${ }^{210}$ Po activity. 

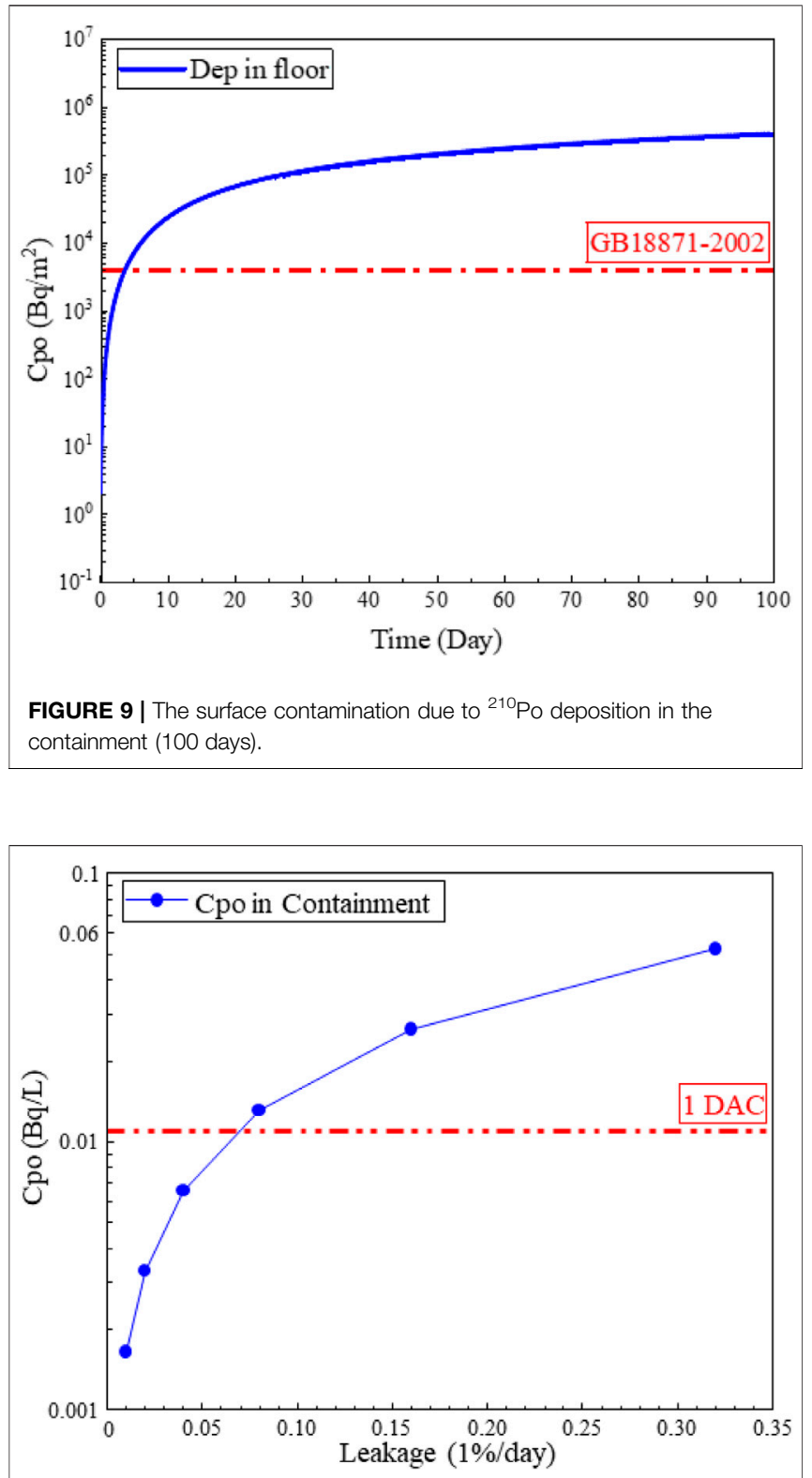

FIGURE 10 |Average activity of ${ }^{210} \mathrm{Po}$ in the containment under different leakage rates of cover gas.

\section{Purification System}

IPPE developed the techniques of the alkaline extraction of polonium from LBE (Yefimov et al., 1997). And MIT developed the polonium extraction techniques of rare-earth filtering and polonium hydride stripping (Larson, 2002). All these research studies show that the extraction and purification efficiency of ${ }^{210} \mathrm{Po}$ in a real LFR have the potential to reach 90-99\%. Therefore, it is reasonable to assume a purification efficiency of $95 \%$ to analyze the sensitivity of purified fraction to the ${ }^{210} \mathrm{Po}$ activity in the containment. While the leakage rate is fixed, we modified the flow fraction into the purification system $(f)$, from 0.01 to 0.2 .

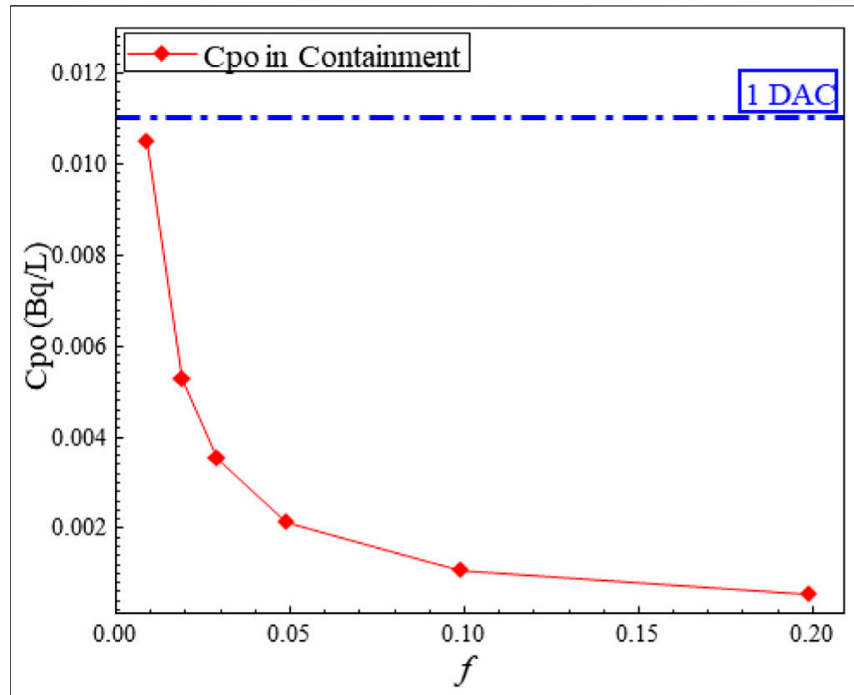

FIGURE 11 | The average activity of ${ }^{210} \mathrm{Po}$ in the containment under different purification fractions.

$$
\lambda_{\text {purify }}=\frac{f m \eta}{M},
$$

where $m$ is the LBE mass flow rate $(\mathrm{kg} / \mathrm{s}), \eta$ is the purification efficiency (\%), and $M$ is the total LBE mass $(\mathrm{kg})$.

Apparently, in Figure 11 above, the purification fraction has a significant influence on the activity of ${ }^{210} \mathrm{Po}$ in the containment. A high purification fraction could reduce the ${ }^{210} \mathrm{Po}$ contamination in the containment effectively, but significantly increase the load of the LBE purification system and the operation cost. While the purification fraction is less than 0.01 , the ${ }^{210} \mathrm{Po}$ concentration will exceed one DAC limit. And while the purification fraction is more than 0.05 , the decrease rate of ${ }^{210} \mathrm{Po}$ in the containment slowed down gradually. To make a compromise between nuclear safety and economy, a purification fraction of $\sim 0.05$ is recommended.

\section{DISCUSSION AND CONCLUSION}

As a summary of the aforementioned simulation results, for a typical LFR, most of the ${ }^{210}$ Po accumulate in the LBE coolant can be restrained as a form of $\mathrm{PbPo}$; only $\sim 10^{-9}$ of them could evaporate into cover gas, which is strongly dependent on the temperature on the LBE-gas interface. The aerosol deposition seems to be a positive feature in that it takes the radioactive ${ }^{210} \mathrm{Po}$ down onto ground and restrains the DAC value in air. However, the surface contamination and aerosol resuspension are newly emerging issues. Ventilation combined with the atmosphere purification system is an artificial and reliable approach for $\mathrm{Po}$ decontamination. 
In addition, some major safety challenges of polonium in LFR still exist. The unknown phenomena and their effects on polonium transport behavior need to be further and deeply explored, such as the oxygen control in LBE, material corrosion products, and impurity filtration. In the next step, more mechanisms of Po transport in the real operation condition and design base accident (DBA) condition will be taken into consideration.

\section{DATA AVAILABILITY STATEMENT}

The raw data supporting the conclusions of this article will be made available by the authors, without undue reservation.

\section{REFERENCES}

Buongiorno, J. (2001). Conceptual Design of a Lead-Bismuth Cooled Fast Reactor with In-Vessel Direct-Contact Steam Generation. MIT. Nuclear Engineering Department. Ph.D Thiesis.

Buongiorno, J., Loewen, E. P., Czerwinski, K., and Larson, C. (2017). Studies of Polonium Removal from Molten Lead-Bismuth for Lead-Alloy-Cooled Reactor Applications. Nucl. Technology. 147 (3), 406-417. doi:10.13182/nt04-a3539

Didier, D. B., Hamid, A. A., Peter, B., and Leysen, P. (2015). The MYRRHA ADS Project in Belgium Enters the Front End Engineering Phase. Phys. Proced. 66, 75-84. doi:10.1016/j.phpro.2015.05.012

Dierckx, M., Van Dyck, D., Vermeeren, L., and Bogaerts, W. (2014). Research towards Ultrasonic Systems to Assist In-Vessel Manipulations in Liquid Metal Cooled Reactors. IEEE Trans. Nucl. Sci. 61 (4), 2024-2033. doi:10.1109/ tns.2014.2303951

Feuerstein, H., Oschinski, J., and Horn, S. (1992). Behavior of Po-210 in Molten Pb-17Li. J. Nucl. Mater. 191-194, 288-291. doi:10.1016/s00223115(09)80052-4

IAEA (2019). Nuclear Power Reactors in the World. Reference Data No. 2.

Koloszar, L., Buckingham, S., and Planquart, P., (2015). MyrrhaFoam: A CFD Model for the Study of the thermal Hydraulic Behavior of MYRRHA, 16. Chicago, IL: NURETH-.

Koloszar, L., Buckingham, S., and Planquart, P., (2014). CFD Simulation of the Thermohydraulic of the MYRRHA ReactorTHINS 2014 International Workshop. Modena, Italy.

Larson, C. L. (2002). Polonium Extraction Techniques for a Lead-Bismuth Cooled Fast Reactor, Doctoral dissertation. Cambridge, USA: Massachusetts Institute of Tehcnology. Master Thesis.

Li, N., Yeifimov, E., and Pankratov, D. (1998). Polonium Release from an ATW Burner System with Liquid Lead-Bismuth Coolant. Los Alamos Natl. Lab., 836, 1-10.

Loewen, E. (2005). Investigation of Polonium Removal Systems for Lead-Bismuth Cooled FBRs. Prog. Nucl. Energ. 47, 586-595. doi:10.1016/ j.pnucene.2005.05.061

Lorusso, P., Bassini, S., Del Nevo, A., Di Piazza, I., Giannetti, F., Tarantino, M., et al. (2018). GEN-IV LFR Development: Status \& Perspectives. Prog. Nucl. Energ. 105, 318-331. doi:10.1016/j.pnucene.2018.02.005

Mao, L. (2014). Preliminary Analysis of Polonium-210 Behavior for Lead-based Reactor. Hefei, China: University of Science and Technology of China. Master Thesis.

\section{AUTHOR CONTRIBUTIONS}

DL: paper writing, data preparation, and systematic analysis. WY: program coding and sensitivity analysis. ZZ and HB: validation and verification. HJ and WJ: module coding. NM: theoretical model development.

\section{FUNDING}

This study was funded by the National Defense Pre-Research Foundation of China (grant no. 201-XXXX0404-fzsdx-Tm06) and the Fundamental Science on Nuclear Wastes and Environmental Safety Laboratory (grant no. 18kfhk04).

Nuclear Regulatory Commission 10Cfr. (2017). Available at: http://www.nrc. gov/reading-rm/doc-collections/cfr/part020/appb/polonium-210.html. 2017 Accessed March 25, 2021.

Pankratov, D. V., Efimov, E. I., Toshinskii, G. I., and Ryabaya, L. D. (2004). Analysis of the Polonium Hazard in Nuclear Power Systems with Lead-Bismuth Coolant. At. Energ. 97 (2), 559-563. doi:10.1023/b:aten.0000047682.88612.e1

Ram, R., Vaughan, J., Etschmann, B., and Brugger, J. (2019). The Aqueous Chemistry of Polonium (Po) in Environmental and Anthropogenic Processes. J. Hazard. Mater. 380, 120725. doi:10.1016/j.jhazmat.2019.06.002

Yefimov, E., Pankratov, D., and Ignatiev, S. (1997). Removal and Containment of High-Level Radioactive Polonium from Liquid Lead-Bismuth Coolant. MRS Proc. 506, 679. doi:10.1557/PROC-506-679

Zrodnikov, A. V., Toshinsky, G. I., and Komlev, O. G., (2008). Innovative Nuclear Technology Based on Modular Multi-Purpose Lead-Bismuth Cooled Fast Reactors. Prog. Nucl. Energ. 50 (2-6), 170-178. doi:10.1016/ j.pnucene.2007.10.025

Zrodnikov, A. V., Toshinsky, G. I., Komlev, O. G., Stepanov, V. S., and Klimov, N. N. (2011). SVBR-100 Module-type Fast Reactor of the IV Generation for Regional Power Industry. J. Nucl. Mater. 415, 237-244. doi:10.1016/j.jnucmat.2011.04.038

Conflict of Interest: The authors DL, ZZ, and HB were employed by the company Nuclear Power Institute of China.

The remaining authors declare that the research was conducted in the absence of any commercial or financial relationships that could be construed as a potential conflict of interest.

Publisher's Note: All claims expressed in this article are solely those of the authors and do not necessarily represent those of their affiliated organizations, or those of the publisher, the editors and the reviewers. Any product that may be evaluated in this article, or claim that may be made by its manufacturer, is not guaranteed or endorsed by the publisher.

Copyright (C) 2021 Lilin, Yuqing, Zian, Bochen, Jiewei, Jianbo and Muyi. This is an open-access article distributed under the terms of the Creative Commons Attribution License (CC BY). The use, distribution or reproduction in other forums is permitted, provided the original author(s) and the copyright owner(s) are credited and that the original publication in this journal is cited, in accordance with accepted academic practice. No use, distribution or reproduction is permitted which does not comply with these terms. 